http://jmscr.igmpublication.org/home/ ISSN (e)-2347-176x ISSN (p) 2455-0450

crossref DOI: https://dx.doi.org/10.18535/jmscr/v9i1.25

Journal Of Medical Science And Clinical Research

\title{
Comparative Study of Sensitivity and Specificity of Ultra Sonagraphy and Computed Tomographyin Clinically Suspected Acute Appendicitis as Adiagnostic Tool and Further Confirmed and Correlated with HPE
}

\author{
Authors \\ Dr P. Rajeswari, MD, DCP ${ }^{1}$, Dr G. Kavithal, MS (General Surgery) ${ }^{\mathbf{2}^{*}}$ \\ ${ }^{1}$ Associate Professor, Department of Pathology, Government Erode Medical College Hospital, Erode \\ ${ }^{2}$ Assistant Professor, Department of General Surgery, Government Erode Medical College, Erode \\ *Corresponding Author \\ Dr G. Kavithal \\ Assistant Professor, Department of General Surgery, Government Erode Medical College, Erode
}

\begin{abstract}
Introduction: The vermiform appendix, which for a long time was thought as a vestigial organ turned out to be an immunological organ. Immunoglobulin $A$ is the predominant immunoglobulin secreted by the appendix. The acute inflammation of this organ is called as Acute appendicitis. Surgical emergency is supposed to be acute appendicitis. The diagnosis is based mainly on clinical exam. But now the drastic improvement in imaging techniques has been $h$. This prospective study compares the sensitivity and specificity of Ultrasonography and Computed tomography, as a diagnostic tool in the patients clinically diagnosed as acute appendicitis and confirmed and correlated with histopathological examination post operatively.

Study Design: First nearly One hundred and forty-nine patients with symptoms of abdominal pain, vomiting, fever was selected and the Alvarado scoring system was followed. Patients who had scoring above seven were considered. All patients underwent Ultrasonogram. Those who did not show appendicitis were taken for computerised tomogram. All patients who were diagnosed by the imaging techniques and the clinically suspected acute appendicitis were taken up for the procedure. After the surgery the specimen taken for histopathological examination and the results compared.

Results: For ultrasonography, the sensitivity was $65 \%$, the specificity was $77 \%$, the positive predictive value was $92 \%$, and the negative predictive value was $38 \%$. Comparatively for Computerised tomogram the sensitivity was $93 \%$, the specificity was $94 \%$, the positive predictive value was $97 \%$, and the negative predictive value was $87 \%$. The combined values for ultrasonography and computed tomography (in inconclusive ultrasonographic cases only) was sensitivity 98\% , specificity 70\% , positive predictive value $93 \%$, negative predictive value was $86 \%$ and the most important, diagnostic accuracy was $92 \%$.

Conclusion: In diagnosing acute appendicitis the computed tomogram is found to be better than ultrasonogram. So, we can combine computed tomography with ultra-sonogram for only patients who are inconclusive with ultra-sonogram, thereby saving cost, radiation, time, and manpower.

Keywords: Histo pathological examination, Alvarado scoring, ultra-sonogram (USG), sensitivity, specificity, Computerised tomogram (CT).
\end{abstract}




\section{Introduction}

In surgical ward, the commonest cause of acute abdomen is Acute appendicitis, particularly in young adults. And so the frequent surgery done is appendicectomy. The first major surgery done by any surgeon will be invariably appendicectomy. Though the advances in radiographic studies has improved the diagnostic accuracy, we still rely on clinical examination mainly. A great observation, knowledge in surgical science, and clinical acumen is needed. Even though the combined technique had high predictive value, computed tomogram is reserved for cases who are inconclusive in ultrasonogram so that radiation exposure is prevented and also cost effective.

A prospective study was designed to compare the sensitivity and specificity of USG and CT as a diagnostic tool in clinically suspected cases of acute appendicitis which is further confirmed and correlated with the histopathological examination.

\section{Objective}

1. The sensitivity and specificity of USG in diagnosing clinically suspected case of acute appendicitis as a diagnostic tool is determined and correlated and confirmed with HPE.

2. The sensitivity and specificity of CT indiagnosing clinically suspected patient with acute appendicitis determined as a diagnostic tool and correlated and confirmed further with HPE.

3. Comparing the combined accuracy of USG and CT in clinically suspected case of appendicitis and further confirming with HPE.

\section{Materials and Methods}

The study was done in government erode medical college for a period of one year and the approval of the hospital's ethical committee for human studies. Got before the procedure. Patients who presented with abdominal pain and those who are above 13 years were considered.
After evaluating all the patients, those who had typical signs and symptoms of acute appendicitis and whose Alvarado scoring was above seven were taken up for the study. The patients were explained about the radiological procedures they are going to undertake, the logistics of the study was explained, and consent was obtained. Patients who had other diagnosis were treated accordingly. The age, sex, complaints, ALVARADO score, USG report, CT report, findings in surgery and HPE report post operatively were noted. In the 149 patients taken up for the study and scanned with USG, 82 were positive for appendicitis and 4 had mass formation and so interval appendicectomy was decided for them.52patients were inconclusive with USG and 15 had alternate diagnosis. So the remaining 67 patients (USG inconclusive and other diagnosis) were made to undergo CT imaging. CT had 41 positives, 11 negative and the other 15 had alternate diagnosis. So the USG positive (82), CT positive (41) and 11 patients who were clinically suspected was taken up for surgical procedure. The total comes to 134 . In 134 cases taken for surgery, 124 cases were positive for acute appendicitis and ten looked with no signs of appendicitis. In the 124 cases, there was two gangrenous appendicitis, seven perforation and faecolith was ten, and two had mass formation.

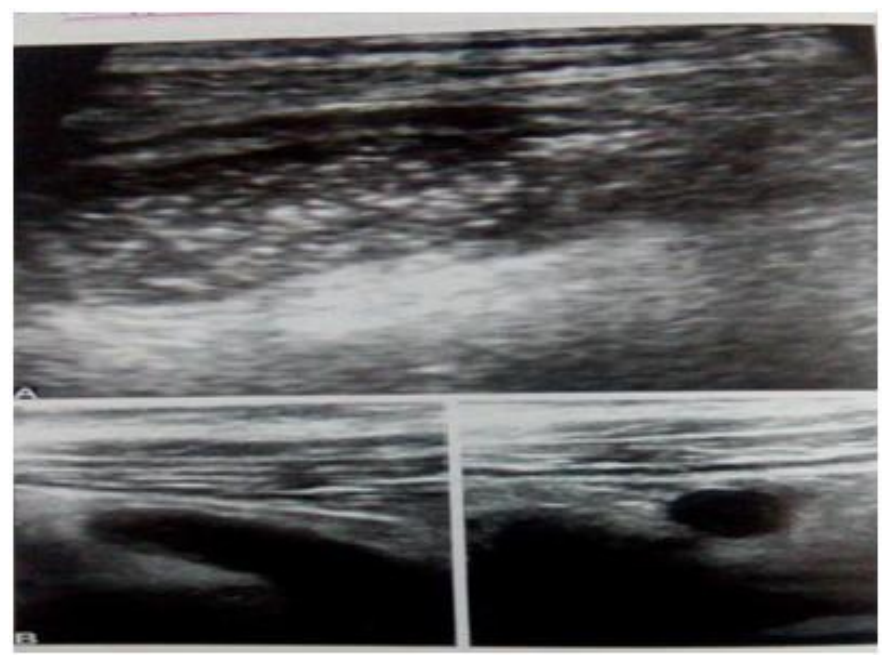




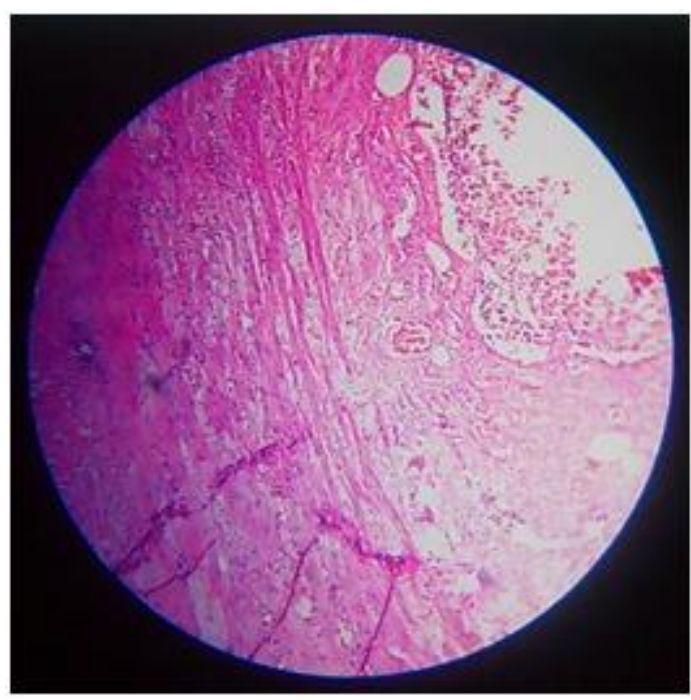

In the post-operative period few patients had complications like respiratory tract infection, infection at surgical sight and one patient had faecal fistula.

\section{Histology showing acute appendicitis}

Infiltration of the muscularispropria by the neutrophil granulocytes is the important finding in diagnosing acute appendicitis. The specimen which had this finding were marked positive and others were marked negative. The patients follow up was done for six weeks.

\section{Statistical Analysis}

With the gathered information's and details the statistical analysis was done. For USG and CT the calculation of Sensitivity, specificity, positive predictive and negative predictive values and the calculation of accuracy for USG, CT and combined Diagnostic pathway (using USG and CT in USG negative or inconclusive cases) was calculated and results tabulated.

\begin{tabular}{|c|c|c|c|}
\hline Statistics & USG & CT & USG+CT \\
\hline Sensitivity & $65 \%$ & $93 \%$ & $98 \%$ \\
\hline Specificity & $77 \%$ & $94 \%$ & $70 \%$ \\
\hline $\begin{array}{c}\text { + Predictive } \\
\text { Value }\end{array}$ & $92 \%$ & $97 \%$ & $93 \%$ \\
\hline $\begin{array}{c}\text {-Predicative } \\
\text { Value }\end{array}$ & $38 \%$ & $87 \%$ & $86 \%$ \\
\hline Accuracy & $68 \%$ & $93 \%$ & $92 \%$ \\
\hline
\end{tabular}

\section{Results}

Chart

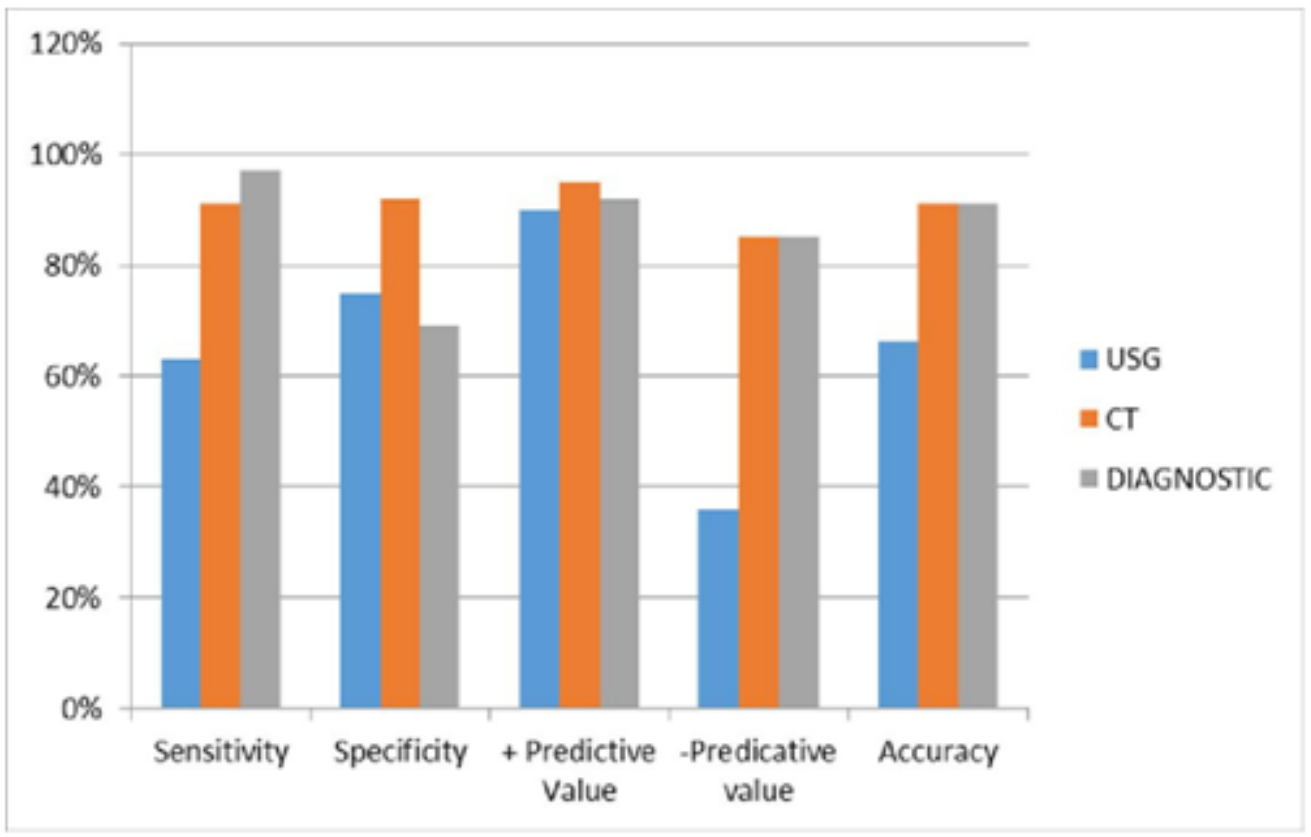




\section{Discussion}

The total number of patients with abdominal pain was 469.In the patients the Alvarado scoring system followed and patients with scoring above seven was considered. In the above group, 187 patients had the score above seven.

These patients (187) were explained about their condition and the investigation and the treatment plan. And the details of the study were clearly explained. Out of these 149 patients gave their consent for the study.

In the 149 patients, USG positive was 82and inconclusive was 67.In this 74 became HPE positive. In the 67 inconclusive patients, CT was done. 41was positive and inconclusive was 11 . other diagnosis was 15.In the $41 \mathrm{CT}$ positive patients, histo pathological examination became positive for 39 and negative for 2 .

\section{Conclusion}

In this study clinically suspected cases of acute appendicitis were taken and the sensitivity and the specificity of USG and CT in diagnosing acute appendicitis was studied and also the combined efficacy was studied and further confirmed and correlated with the post-operative HPE. The results of USG was sensitivity $65 \%$ and the specificity $77 \%$. The results of CT was sensitivity $91 \%$ and the specificity was $92 \%$. On combining USG with CT (When USG was inconclusive) the sensitivity was $98 \%$ and the specificity was $70 \%$. Hence, we conclude:

1. CT is the best in diagnosing acute appendicitis

2. Clinical examination is more important in diagnosis.

3. USG is resorted when findings are equivocal.

4. If USG is not in favour of our clinical diagnosis, then doing $\mathrm{CT}$ is the next best option.

5. So acute appendicitis is diagnosed by clinical, sonographical, and Radiological methods combined.
Bibliography

1. Bent $S$ et al: Does this woman have acute uncomplicated urinary tract infection? JAMA 287:2701, 2002[PMID: 12020306

2. Fihn SD: Clinical practice. Acute uncomplicated urinary tract infection in women. N Engl J Med 349:259, 2003[PMID: 12867610]

3. Hooton TM et al: Diagnosis, prevention, and treatment of catheter-associated urinary tract infection in adults: 2009 international clinical practice guidelines from the Infectious Diseases Society of America. Clin Infect Dis 50:625, 2010 [PMID: 20175247]

4. Le BV, Schaeffer AJ: Genitourinary pain syndromes, prostatitis, and lower urinary tract symptoms. Urol Clin North Am 36:527, 2009[PMID: 19942050]

5. Treggiari MM, Martin DP, Yanez ND, et al. Effect of intensive care unit organizational model and structure on outcomes in patients with acute lung injury. Am J Respir Crit Care Med. 2007; 1;176(7):685-690.

6. Singh N, Falestiny MN, Rogers P, et al. Pulmonary infiltrates in the surgical ICU. Chest 1998;114:1129- 1136.

7. Marino (2006), pp 435bauer TT, torres A. Acute respiratory distress syndrome and nosocomial pneumonia. Thorax 1999;54:1036- 1040

8. Bakowitz, Magdalena (August 2012). "Acute lung injury and the acute respiratory distress syndrome in the injured patient" (http://www.sjtrem.com/content/20/1/54). Scandinavian Journal ofTrauma, Resuscitation and Emergency Medicine. doi:10.1186/1757-7241-20-54 (http://dx. doi. org/ 10.1186 \% 2F1757-7241-20-54).

9. Marino (2006), pp 435Acute respiratory distress syndrome: the Berlin Definition. ARDS Definition Task Force, Ranieri VM, Rubenfeld GD, Thompson BT, Ferguson 
ND, Caldwell E, Fan E, Camporota L, Slutsky AS. JAMA. 2012 Jun20;307(23): 2526-33. doi: 10.1001/jama.2012.5669. PMID 22797452

10. The Berlin definition of ARDS: an expanded rationale, justification, and supplementary material. Ferguson ND, Fan E, Camporota L, Antonelli M, Anzueto A, Beale R, Brochard L, Brower R,Esteban A, Gattinoni L, Rhodes A, Slutsky AS, Vincent JL, Rubenfeld GD, Thompson BT, Ranieri VM. Intensive Care Med. 2012 Oct;38(10):1573-82. Epub 2012 Aug 25. Erratum in: Intensive Care Med. 2012 Oct;38(10):1731-2. PMID 22926653

11. Fan E, NeedhamDM,Stewart TE. Ventilator management of acute lung injury and acute respiratory distress syndrome. JAMA 1999;282:54-61

12. Potkin RT, Swenson ER. Resuscitation from severe acute hypercapnia: determinants of tolerance and survival. Chest 1992;102:1742- 1745

13. Broaddus VC, Berthiaume Y, BiondiJW,et al. Hemodynamic management of the adult respiratory distress syndrome. $\mathrm{J}$ intensive care med 1987;2:190-213

14. Hebert PC, Blajchman MA, Cook DJ, et al. Do blood transfusions improve outcomes related to mechanical ventilation? Chest 2001;119:1850-1857

15. Goodnough LT. Risks of blood transfusion. Crit care med 2003;31(suppl):s678 - s686.

16. The national heart, lung and blood institute ARDS clinical network. Higher versus lower positive end expiratory pressure in patients with acute respiratory distress syndrome. N Eng J Med 2004;351:327336.

17. Meduri GU, chin A. Fibriniproliferation in late adult respiratory distress syndrome. Chest 1994;105(suppl):S127 - S129.
18. McIntyre RC Jr, pulido EJ, Bensard DD, et al. Thirty years of clinical trials in acute respiratory distress syndrome. Crit care med 2000;28:3314-3331.

19. Montgomery AB, Stager MA, carrico J, et al. Causes of mortality in patients with adult respiratory distress syndrome. Am Rev Respir Dis 1985;132:485-489.

20. Barlett RH, Morris AH, Fairley B, et al. A prospective study of acute hypoxic respiratory failure. Chest 1986;89:684689.

21. Gillespie DJ, Marsh HMM, Divertie MB, et al. Clinical outcome of respiratory failure in patients requiring prolonged (24 hours) mechanical ventilation. Chest 1986;90:364 - 369

22. Suchyta MR, Clemmer TP, Elliot CG, et al. The adult respiratory syndrome: a report of survival and modifying factors. Chest 1992;101:1074-1079

23. Rubenfeld GD, Caldwell, Peabody E,et al. Incidence and outcomes of acute lung injury. N Engl J med 2005; 353:1685 1693.

24. Lim W, Qushmaq I, Cook DJ, Crowther MA, Heels-Ansdell D, et al. (2005) Elevated troponin and myocardial infarction in the intensive care unit: a prospective study. Crit Care 9: R636-644.

25. Montgomery AB, Stager MA, carrico J, et al. Causes of mortality in patients with adult respiratory distress syndrome. Am Rev Respir Dis 1985;132:485-489.

26. Barlett RH, Morris AH, Fairley B, et al. A prospective study of acute hypoxic respiratory failure. Chest 1986;89:684689.

27. Gillespie DJ, Marsh HMM, Divertie MB, et al. Clinical outcome of respiratory failure in patients requiring prolonged (24 hours) mechanical ventilation. Chest 1986;90:364 - 369

28. Suchyta MR, Clemmer TP, Elliot CG, et al. The adult respiratory syndrome: a 
report of survival and modifying factors.

Chest 1992;101:1074-1079

29. Rubenfeld GD, Caldwell, Peabody E,et al. Incidence and outcomes of acute lung injury. N Engl J med 2005; 353:1685 1693.

30. Lim W, Qushmaq I, Cook DJ, Crowther MA, Heels-Ansdell D, et al. (2005) Elevated troponin and myocardial infarction in the intensive care unit: a prospective study. Crit Care 9: R636-644. 